\title{
The current aetiology of malignant pleural effusion in the Western Cape Province, South Africa
}

\author{
C F N Koegelenberg, ${ }^{1}$ MB ChB, MMed (Int), FCP (SA), FRCP (UK), Cert Pulm (SA), PhD; S M Bennji ${ }^{1}$ MD, FCP (SA), MMed (Int); \\ E Boer, ${ }^{1}$ MB ChB; P T Schubert, ${ }^{2}$ MB ChB, FCPath (Anat) (SA), MMed (Anat Path), MSc Med Sc (Cytopath), MPhil (Paed Path); \\ J A Shaw, ${ }^{1}$ MB ChB, FCP (SA), MMed (Int); B W Allwood, ${ }^{1}$ MB ChB, FCP (SA), MPH, Cert Pulmonology (SA), PhD; \\ E M Irusen, ${ }^{1} \mathrm{MB} \mathrm{ChB}, \mathrm{FCP}(\mathrm{SA}), \mathrm{PhD}$ \\ ${ }^{1}$ Division of Pulmonology, Department of Medicine, Faculty of Medicine and Health Sciences, Stellenbosch University and Tygerberg Academic \\ Hospital, Cape Town, South Africa \\ ${ }^{2}$ Division of Anatomical Pathology, Department of Pathology, Tygerberg Academic Hospital, National Health Laboratory Service and Faculty of \\ Medicine and Health Sciences, Stellenbosch University, Cape Town, South Africa
}

Corresponding author: C F N Koegelenberg (coeniefn@sun.ac.za)

Background. Malignant pleural effusion (MPE) represents a very common cause of pleural exudates, and is one of the most challenging pleural disorders to manage. This could be attributed to the paucity of high-quality experimental evidence, and inconsistent practice worldwide. South Africa (SA) currently has no data regarding the aetiology of MPE.

Objectives. To identify the most common malignancies causing MPE in a population served by a large tertiary hospital in SA, and specifically the relative contribution of mesothelioma. A secondary objective was to evaluate the efficacy of chemical pleurodesis in a subset of patients.

Methods. We retrospectively included all known cases of MPE evaluated at our institution over a 3-year period with a tissue diagnosis of MPE. Results. The most common causes of MPE in a total of 274 patients were lung cancer ( $n=174,63.5 \%)$, breast cancer $(n=32,11.7 \%)$, unknown primary $(n=22,11.7 \%)$ and mesothelioma $(n=27,9.9 \%)$. Talc pleurodesis was performed in 81 of 194 patients $(41.8 \%)$ referred to our division, and was radiologically successful in 22 of 25 (88.0\%) followed up to 3 months.

Conclusions. The main cause of MPE in our setting was lung cancer, followed by breast cancer, unknown primary and mesothelioma. Chemical pleurodesis was a viable palliative measure for MPE in this population.

S Afr Med J 2018;108(4):275-277. DOI:10.7196/SAMJ.2018.v108i4.12914

Malignant pleural effusion (MPE) not only represents a very common cause of pleural exudates, but is also one of the most challenging pleural disorders to manage, given the paucity of highquality evidence and the heterogeneity of practice worldwide. ${ }^{[1,2]}$ Between $30 \%$ and $50 \%$ of all patients with metastatic malignancies will have pleural involvement at autopsy, and approximately half of these will have pleural effusions, which range from insignificant to massive. ${ }^{[2,3]}$

MPE may complicate most malignancies, although lung and breast cancer remain the most common causes. ${ }^{[2]}$ Evidence suggests that MPE is most often caused by haematogenous spread of malignant cells to the visceral pleura with secondary seeding to the parietal pleura. ${ }^{[4]}$ MPE generally signifies incurable disease with a poor prognosis. ${ }^{[2]}$ Median survival is $\sim 3-12$ months, but can vary significantly according to cell type, performance status of the patient, staging and whether a chemosensitive malignancy is present. ${ }^{[2]}$ The two most common non-surgical interventions are intercostal drainage (ICD) with pleurodesis to obliterate the pleural space, or indwelling pleural catheters (IPCs) that provide continuous drainage of the pleural cavity and may potentially cause autopleurodesis. ${ }^{[2,5]}$

We previously showed that adenocarcinoma had surpassed squamous cell carcinoma as the predominant cell type in lung cancer patients in our setting, which is in keeping with international trends. ${ }^{[6,7]}$ To the best of our knowledge, there are no data regarding the aetiology of MPE for either the Western Cape Province or South Africa (SA).

\section{Objectives}

The primary objective of this study was to identify the most common pleural malignancies leading to MPE in the population served by a large tertiary hospital in the Western Cape, and specifically the relative contribution of mesothelioma. The secondary objective was to evaluate the radiological efficacy of chemical pleurodesis, which was offered to selected patients.

\section{Methods}

Study design and population

We retrospectively identified and included all known cases of MPE, defined as malignant cells present on pleural fluid analysis or pleural biopsy, that were managed at our institution from January 2014 to December 2016. We identified: (i) cases managed by the Division of Pulmonology at Tygerberg Academic Hospital; and (ii) all other known cases (not referred to our division) with a cytological or histological diagnosis of MPE made by the Division of Anatomical Pathology, Tygerberg Academic Hospital, National Health Laboratory Service (NHLS). Tygerberg Academic Hospital is a 1380 -bed facility in Cape Town, SA. It is one of two referral centres in the city and renders a tertiary service to a population of $\sim 3.0$ million people. We used the hospital's existing lung cancer registry to identify all cases of pleural malignancy presented at the lung cancer board meeting as well as the theatre records to identify any potential patients who underwent pleural procedures related to MPE. We also searched the NHLS records to specifically identify all other cases that 
were not managed by the division. Duplicate entries were removed if encountered.

\section{Ethics approval}

The study was conducted in accordance with the principles outlined in the Declaration of Helsinki and local and international good clinical practice guidelines. Ethical approval was obtained from the Health Research Ethics Committee of Stellenbosch University (ref. no. S15/10/233).

\section{Primary diagnoses and further analyses}

Primary underlying diagnoses were based on confirmatory cytology/ histology with definitive imaging and/or immunohistochemistry/ immunocytochemistry profiling of malignant cells, or a known history of active extrapleural malignancy (with proven spread to the pleura).

\section{Imaging}

We categorised the size of pleural effusion on the chest radiograph into three categories: small (less than one-third of the hemithorax), moderate (one-third to two-thirds of the hemithorax) and large (more than two-thirds of the hemithorax). Computed tomography scans, when available, were reviewed and evaluated for pleural thickening (defined as $\geq 10 \mathrm{~mm}$ ) and nodularity of both visceral and parietal layers, diaphragmatic thickening (defined as a diaphragmatic diameter $>7 \mathrm{~mm}$ ), and liver metastasis.

Table 1 . The causes of malignant pleural effusion $(N=274)$

\begin{tabular}{lll}
\hline Causes & Tissue type & $\boldsymbol{n}(\%)$ \\
\hline Primary & Mesothelioma & $27(9.9)$ \\
& Other & 0 \\
Secondary & Lung & $174(63.5)$ \\
& Adenocarcinoma & $115(66.1)$ \\
Squamous cell & $15(8.6)$ \\
NSCLC - non-specified & $20(11.5)$ \\
Undifferentiated/large cell & $3(1.7)$ \\
$\quad$ SCLC & $21(12.1)$ \\
& Breast & $32(11.7)$ \\
Unknown primary & $22(8.0)$ \\
Gynaecological & $9(3.3)$ \\
Gastrointestinal & $3(1.1)$ \\
Lymphoma & $3(1.1)$ \\
Other & $4(1.5)$ \\
*Skin cancer $(n=1)$, prostate cancer $(n=1)$, sarcoma $(n=1)$, renal cell carcinoma $(n=1)$.
\end{tabular}

\section{Pleurodesis}

Pleurodesis was routinely offered to patients with symptomatic MPE, provided they experienced relief of dyspnoea after thoracentesis, had no trapped lung and had a predicted life expectancy of $>3$ months. Patients who underwent chemical pleurodesis using talc slurry were identified from the division's records, and the radiological success rate at 3-month follow-up was documented. Successful pleurodesis was defined as lack of reaccumulation of pleural fluid collection.

\section{Statistical analysis}

Descriptive statistics and $\chi^{2}$ comparisons of proportional data were performed. A $p$-value $<0.05$ in a two-tailed test of proportions $\left(\chi^{2}\right)$ was considered significant. The data were presented as means (standard deviation (SD)).

\section{Results}

A total of 274 cases (mean age 59.3 (SD 12.5) years, 123 males) of MPE were identified: 194 from the division's records (an average of 65 per year) and a further 80 from the NHLS database. The primary underlying diagnoses are summarised in Table 1, with the most common being lung cancer $(n=174,63.5 \%)$, breast cancer $(n=32$, $11.7 \%$, malignant mesothelioma $(n=27,9.9 \%)$ and unknown primary $(n=22,11.7 \%)$.

Table 2 provides a summary of the radiological findings. The size of pleural effusion in patients with mesothelioma was mainly large ( $n=11,52.3 \%$ of all mesothelioma patients), followed by moderate $(n=7,33.3 \%)$ and small $(n=3,14.2 \%)$. In lung cancer, the size was approximately equally spread from small to large. In breast cancer, moderate-sized effusions $(n=12,46.1 \%)$ were the most common. Pleural thickening and nodularity in mesothelioma were parietal $(n=11,52.3 \%)$ and visceral $(n=9,42.8 \%)$.

Chemical pleurodesis was performed in 81 of 194 cases (41.8\%) managed by our division, and was successful in 22 (88.0\%) of 25 patients followed up at 3 months.

\section{Discussion}

In our patient population, the most common causes of MPE were lung cancer (63.5\%), breast cancer (11.7\%), unknown primary (11.7\%) and mesothelioma (9.9\%). In patients who were offered chemical pleurodesis and followed up for at least 3 months, pleurodesis was successful in nearly $90 \%$.

Our findings are in line with international trends, with the one exception being the relatively small proportion of lymphomas. ${ }^{[2]}$ This is surprising, given the relatively high prevalence of HIV infection in our population and the known association between HIV and lymphomas. ${ }^{[8]}$ Possible explanations may include lack of referral

Table 2. Radiological features of malignant pleural effusion $(N=194), \%$

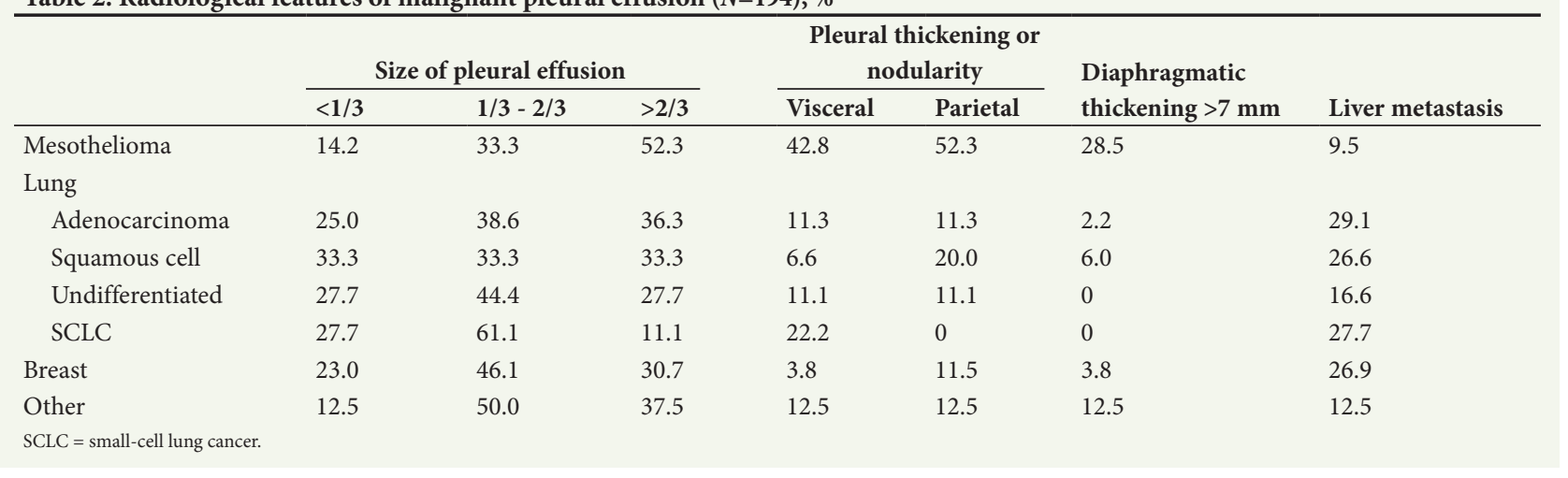


from outside doctors, owing to misdiagnoses as pleural tuberculosis or presumptive diagnoses of pleural involvement in patients known to have lymphoma and imaging compatible with pleural spread (e.g. positive positron emission tomography-computed tomography). We also did not observe a female predominance as is sometimes reported ${ }^{[9]}$ arguably because in our cohort breast cancer was only responsible for just over $10 \%$ of MPEs.

The fact that 1 in 10 MPEs were in patients with malignant mesothelioma, almost a decade after asbestos was finally banned in SA, remains a significant finding. ${ }^{[10]}$ The latency period after exposure to asbestos is known to be very prolonged, with almost all cases seen $\geq 15$ years after exposure. ${ }^{[11]}$ Moreover, the estimated median latent period is at least 30 years after the initial exposure. ${ }^{[11]}$

The incidence of mesothelioma peaked around 2015 in the UK, but in contrast may continue to increase in resource-limited settings secondary to poor regulation of industrial and household utilisation of asbestos. ${ }^{[12]}$ Mesothelioma is therefore expected to continue to account for a significant proportion of MPE in our setting for at least another two to three decades.

The two most common approaches to MPE are IPCs or chemical pleurodesis via rigid or semirigid thoracoscopy or ICD. ${ }^{[2]}$ IPCs were only introduced to our service in the latter half of 2015, and pleurodesis was therefore the most common form of palliation offered for dyspnoea during the study period. The proportion of patients offered pleurodesis (41.8\%) as well as the 3-month radiological success rate of $88.0 \%$ are on par with reported figures, which generally range from $30 \%$ to $50 \%$ and from $75 \%$ to $90 \%$, respectively. ${ }^{[9]}$

\section{Study strengths and limitations}

One of the strengths of our study is the fact that we did not limit our cohort to patients referred to our unit. We anticipated that a significant proportion of patients would be managed by other disciplines, which proved to be the case in 80 of 274 cases. An obvious limitation is the retrospective nature of the study and possible selection bias, as patients with advanced malignancy may have been referred directly for palliative care, without further investigations. Further, loss to follow-up in the pleurodesis group limits the conclusions with regard to the apparent high success rate of chemical pleurodesis. Our sample size was restricted to cases seen over a 3-year period, which could limit the general applicability of our findings to the greater SA context.

\section{Conclusions}

We identified that the main cause of MPE was lung cancer, followed by breast cancer, unknown primary and mesothelioma. The proportion of mesothelioma cases was both surprising and concerning. Chemical pleurodesis appears to be a viable palliative measure for MPE in our population.

Acknowledgements. We thank Ms Greta Neethling, who aided in identifying all cases of MPE from the NHLS database.

Author contributions. CFNK initiated the study, analysed the data and wrote the manuscript. SMB, EB, PTS, JAS and BWA assisted with the study design and data collection, and edited the manuscript. EMI critically reviewed the data analysis and edited the final draft of the manuscript.

Funding. None.

Conflicts of interest. None.

1. Heffner J, Klein J. Recent advances in the diagnosis and management of malignant pleural effusions. Mayo Clin Proc 2008;83(2):235. https://doi.org/10.4065/83.2.235

2. Azzopardi M, Porcel MJM, Koegelenberg CFN, Lee YCG, Fysh ETH. Current controversies in the management of malignant pleural effusions. Semin Respir Crit Care Med 2014;35(6):723-731. https://doi.org/10.1586/17476348.2015.1098535

3. Fitzgerald DB, Koegelenberg CFN, Yasufuku K, Lee YCG. Surgical and non-surgical management of malignant pleural effusions. Expert Rev Respir Med. 2018;12(1):15-26. https://doi.org/10.1080/ 17476348.2018.1398085

4. Antony V, Loddenkemper R, Astoul P, et al. Management of malignant pleural effusions. Eur Respir J 2001;18(2):402-419. https://doi.org/10.1183/09031936.01.00225601

5. Fortin M, Tremblay A. Pleural controversies: Indwelling pleural catheter vs. pleurodesis for malignant pleural effusions. J Thorac Dis 2015;7(6):1052-1057. https://doi.org/10.3978/j.issn.20721439.2015.01.51

6. Koegelenberg CFN, Aubeelack K, Nanguzgambo AB, et al. Adenocarcinoma the most common cell type in patients presenting with primary lung cancer in the Western Cape. S Afr Med
J 2011;101(5):2011.

7. Nanguzgambo $\mathrm{AB}$, Aubeelack K, von Groote-Bidlingmaier F, et al. Radiologic features, staging, and operability of primary lung cancer in the Western Cape, South Africa. J Thorac Oncol 2011;6(2):343350. https://doi.org/10.1097/JTO.0b013e3181fd40ec

8. Sissolak G, Seftel M, Uldrick T, Esterhuizen T, Mohamed N, Kotze D. Burkitt’s lymphoma and B-cell lymphoma unclassifiable with features intermediate between diffuse large B-cell lymphoma and Burkitt's lymphoma in patients with HIV: Outcomes in a South African public hospital. J Glob Onco 2016;3(3):218-226. https://doi.org/10.1200/JGO.2015.002378

9. Dresler C, Olak J, Herndon J 2nd, et al. Phase III intergroup study of talc poudrage vs talc slurry sclerosis for malignant pleural effusion. Chest 2005;127(3):909-915. https://doi.org/10.1378 chest.127.3.909

10. National Institute for Occupational Health (division of the National Health Laboratory Service). Asbestos. 2017. http://www.nioh.ac.za/?page=asbetos\&id=26 (accessed 8 November 2017).

11. Lanphear B, Buncher C. Latent period for malignant mesothelioma of occupational origin. J Occup Med 1992;34(7):718-721.

12. Hodgson J, McElvenny D, Darnton A, Price M, Peto J. The expected burden of mesotheliom Hodgson J, McElvenny D, Darnton A, Price M, Peto J. The expected burden of mesothelioma
mortality in Great Britain from 2002 to 2050. Br J Cancer 2005;92(3):587-593. https://doi. org/10.1038/sj.bjc.6602307

Accepted 10 November 2017. 